attachment bonds which is said to produce grief.

The evolutionary viewpoint is also used to regard primitive grief as a deficit reaction, occurring when a significant other is absent, and leading to searching and protest reactions. In adult humans, these reactions then extend to involve complex mental processes, limiting the amount of distressing information that is received. Conventionally, attempts have been made to overcome this kind of equilibrium by 'grief work', but Archer seriously questions the validity of such an approach.

His writing sets contemporary ideas in both cultural and historical contexts, undertakes an extensive review of research, and looks at such specific issues as the loss of a child, parent or friend (in spite of the preference for evolutionary principles). Like many attempts to move a subject on in one significant bound, it promises rather more than it delivers. But no one with a serious interest in grief can afford to ignore it.

Hugh Freeman, former Editor of the British

Journal of Psychiatry, is Honorary Visiting Fellow, Green College, Woodstock Road, Oxford OX2 6HG, UK.

\section{A model subject}

\section{Global Energy and Water Cycles}

edited by K. A. Browning and R. J. Gurney Cambridge University Press: 1999. 292 pp. $\mathfrak{E 5 0 , \$ 9 5}$

\section{David Rind}

The interactions between energy and water cycles are basic to both weather forecasting and climate-change prediction. This book builds on a 1994 conference of the Global Energy and Water Cycle Experiment and attempts to assess our understanding of this interaction for forecasting on both short and long timescales.

Almost all of the relevant processes involved in the water and energy cycle (with the notable exception of sea ice) have their own subsections in the book. These include such diverse fields as numerical schemes for water-vapour advection, cloud physics, the movement of water through the soil and the ocean's response to fresh water. Each section presents cutting-edge science, emphasizes uncertainties and projects what future research is needed and likely.

The book focuses on how a process works and how it can be modelled, especially in the global general circulation models used to predict climate change. The problems are immense. To model the process, we must first understand it, which means we must be able to observe it. Observations of many hydrological processes are quite poor. Using available data, modellers have provided detailed representations of particular

\title{
Science in culture
}

\section{Surely You're Joking, Mr. Feynman (Adventures of a Curious Character)}

a stage performance by Mike Maran Productions

\section{John Polkinghorne}

Richard Feynman is one of a very small band of theoretical physicists whose names have a chance of being recognized by the general public. This is not because of a just appreciation of the powerful calculational techniques that won him a Nobel prize for his work in quantum electrodynamics. Rather, it is because of the persona he created for himself as a fun-loving, bongo-drum-playing guy who just happened to be brilliant at physics. This carefully cultivated image is powerfully conveyed in the best-selling book after which this stage production has been named and from which it draws much of its material.

(Characteristically, the book was compiled from verbal anecdotes by a member of the Leighton family, faithful amanuenses to Feynman, who was himself an actor rather than a playwright.)

Many people have enjoyed the book, though I have to say that, though I am a great admirer of Feynman the physicist, I have never cared for it much. Beneath all the jokiness there is a clear subtext: I am cleverer than anyone else and here are a hundred stories to prove it. But the image of the New York kid was a mask behind which a much more complex and interesting character was concealed. This is evident from the fact that when James Gleick came to write his balanced and successful biography, Genius, he found a detailed and carefully preserved archive available to him - not quite what one might have expected of someone whose public stance was that he would have liked to have ducked out of all the trouble involved in accepting a Nobel prize (a story repeated in this show but one that I have never believed)

Both the persona and something of the man beneath it are displayed in this lively stage production. Its form is essentially that of the cabaret, a succession of stories, accompanied by visual images and punctuated by episodes of the South American rhythms Feynman liked so

processes, with the relevant physics often occurring on very small scales. Whether these processes can be accurately simulated in terms of the larger-scale variables used in general circulation models, what level of detail is needed to make global models useful, and how representations can be made consistent among the different processes are three main themes in this book.

While the level of presentation is quite high, there is no attempt to make the coverage systematic. For example, there is no figure showing the climatological global precipitation field, as uncertain as it is.

This book is most appropriate for researchers and advanced graduate students, since it will update them on the diverse com-

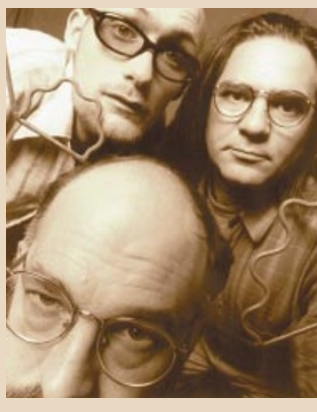

much, skilfully performed on a variety of exotic instruments. There are serious moments - the tragic early death of his first wife Arlene is recalled and there is an account of

Feynman's agonized reaction to the devastation of Hiroshima by the atomic bomb he had helped to build.

Dick Feynman had a deep intuitive understanding of vast ranges of science outside his chosen speciality and a considerable ability to convey insight to non-scientists in a lucid and striking way. In the show, this is best exemplified by his beautiful observation that a tree grows out of the air and not out of the earth, and by his incisive and deceptively simple contribution at the end of his life to the enquiry into the Challenger disaster, identifying the cause as the effect of low temperature on the seals of the fuel compartments.

The production drags a little towards the end of its hour-and-a-half, when a valiant attempt to convey something of the Feynman diagram technique is, almost inevitably, somewhat confused and confusing, and where there is, perhaps, undue recourse to drumming to fill in gaps in the continuity.

Nevertheless, Mike Maran is to be congratulated on a lively contribution to what seems to be a growing genre of dramatic performances with some scientific content. I attended a 4 p.m. performance at which at least half the audience appeared to be under the age of 16. I am sure that these young people will have caught something of the excitement and value of science through this performance, inspired by someone who was both a very great scientist and an accomplished showman.

John Polkinghorne is a former President of Queens' College, Cambridge CB3 9ET, UK.

ponents involved in climate modelling. But state-of-the-art books in rapidly developing fields have a relatively short shelf-life. Significant developments have already occurred in the three years since most of these articles were written. For example, we have seen the launch of the Tropical Rainfall Measurement Mission and a moistureconserving form of the semi-Lagrangian scheme for water-vapour advection has been developed. I estimate that another such book will be needed in around five years. With luck, the editors will consider making this a series.

David Rind is at the NASA Goddard Space Flight Center, Goddard Institute for Space Studies, 2880 Broadway, New York, New York 10025, USA. 